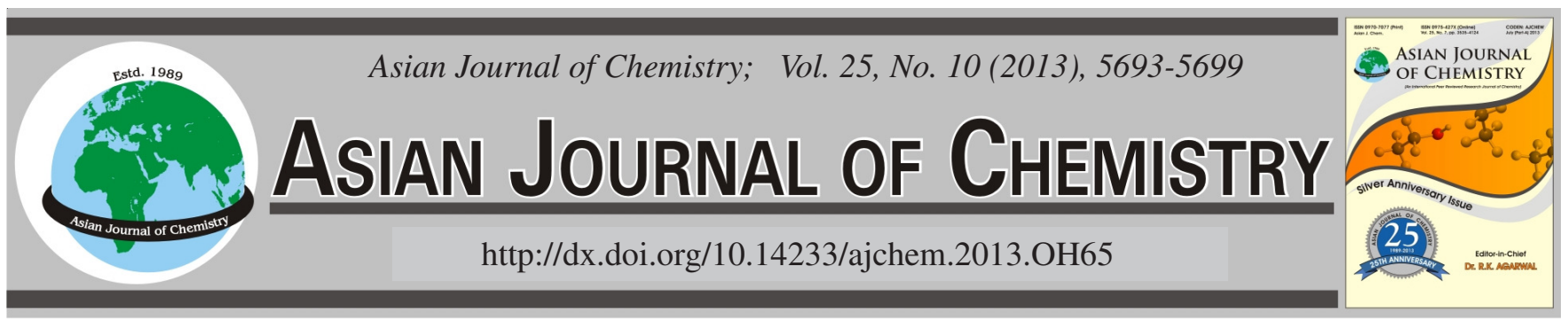

\title{
Study on the Quality Properties of Concrete Using Recycled Sand Produced from Wet Gravity Separation System $\dagger$
}

\author{
SANGSOO LeE* and Hayoung Song \\ Department of Architectural Engineering, Hanbat National University, Daejeon 305-719, Republic of Korea \\ *Corresponding author: E-mail: sslee111@ hanbat.ac.kr
}

\begin{abstract}
This study evaluated recycled sand's properties before and after going through the wet gravity separation system. The mechanical properties, | shrinkage and durability properties of concrete with different replacement ratios of recycled sand, were compared and analyzed. As a result, it was found that the quality and performance of the recycled sand that has gone through the wet gravity separation system were better than those of the recycled sand that has not gone through the system, because of the removal of impurity content and powder content. Looking at the changes in unit-water content for satisfying the fluidity, it was found that the unit-water content of the concrete using the finally produced recycled sand was similar to that of the concrete using natural sand. The concrete using the recycled sand that has gone through the wet gravity separation system compared to the recycled sand that has not gone through the wet gravity separation system, showed superior performance in compressive strength, shrinkage and durability.
\end{abstract}

Key Words: Concrete, Recycled sand, Gravity, Separation.

\section{INTRODUCTION}

Compared to other industries, construction industry consumes a large volume of natural resources. Large quantities of construction waste produced in life cycle of concrete structures, which are new construction, demolition and recycling highlight the need to recycle them to convert construction industry into an environment-friendly industrial structure ${ }^{1}$.

The wastes (wood, paper, cloth, styrofoam, steel, etc.) are not properly sorted at construction waste sites, but are crushed by construction waste disposers. It needs that foreign materials are separated and sorted out through manpower, electromagnets, air blowers and aeration tanks. However, there are large quantities of fine foreign materials in recycled sand produced, which makes it hard to secure the quality. So, they are only used in low value-added purposes such as earth embankment and earth bermed. Or they are dumped or abandoned without recycling.

This study has experimentally and empirically examined the quality properties of the recycled sand produced from sand flux that separates impurity content for recycling construction wastes and the mechanical properties, shrinkage and durability properties of the concrete ${ }^{2,3}$. The purpose of the study was to verify system performance and to provide basic material for increasing the uses and for adding higher value to recycled sand.
Overview of the wet gravity separation system: A sand flux was made to separate and sort out foreign materials by combining foreign material removers applying methods of flux tank and cyclone. The sand flux in this study was designed to primarily separate and sort out foreign materials through the foreign material remover installed at the top by applying the cyclone method ${ }^{4}$. The design enabled recycled sand emitted through this to remove foreign materials at the second phase through the flux tank installed at the bottom. The conceptual map for this equipment in Figs. 1 and 2 shows the processing of the recycled sand production system of an intermediary construction waste disposer that has applied this equipment ${ }^{5-7}$.

\section{EXPERIMENTAL}

Property evaluation and indoor mixing: It is shown the types of the specimens for evaluating fundamental properties of the recycled sand (Table-1). This showed the quality test categories and methods for evaluating the fundamental properties of the recycled fine aggregate.

It is shown that the indoor mixing and measurement categories for comparing and examining the mechanical properties, shrinkage and durability properties of concrete depending on the types of recycled sand (Table-2). 

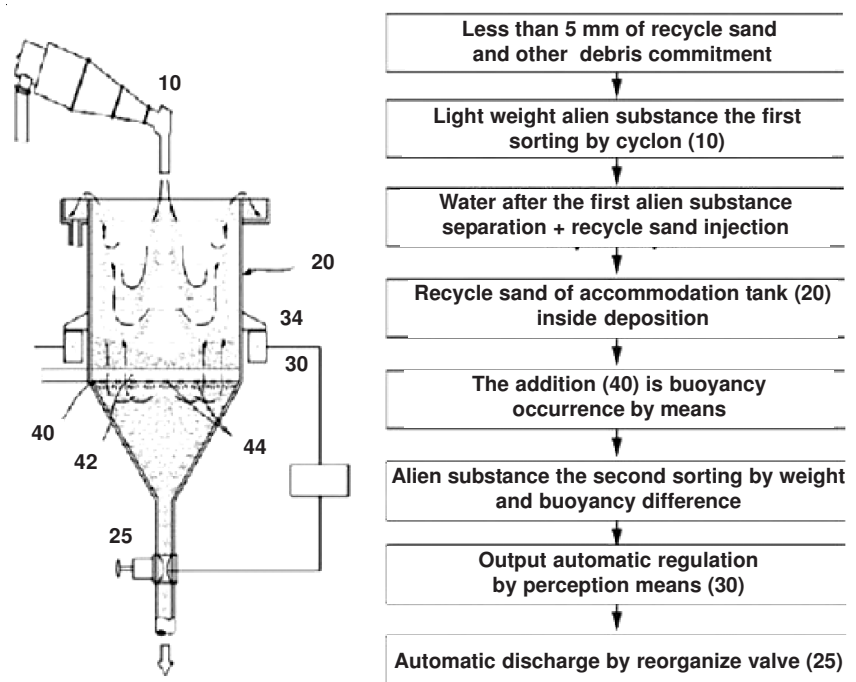

Fig. 1. Concept of the sand flux system
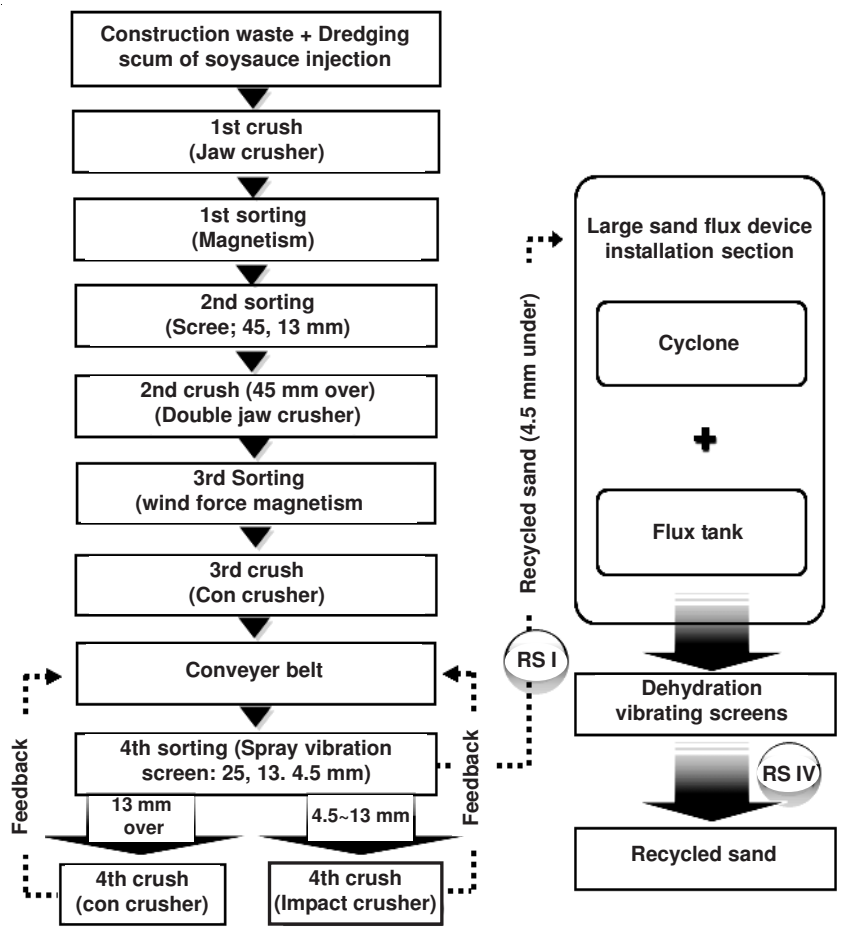

Fig. 2. Manufacturing process of recycled sand of the middle-treatment enterprise of construction waste

\begin{tabular}{ll} 
& \multicolumn{1}{c}{ TABLE-1 } \\
& \multicolumn{1}{c}{ TYPES OF SPECIMENS FOR FUNDAMENTAL } \\
& \multicolumn{1}{c}{ PROPERTIES EVALUATION } \\
\hline Type & Types of Specimens \\
\hline RS-I & $\begin{array}{l}\text { Recycled fine aggregate before sand flux } \\
\text { RS-IV }\end{array}$ \\
\hline
\end{tabular}

Used materials: It is shown that the physical and chemical properties of the materials were used in the study (Table-3).

\begin{tabular}{|c|c|c|}
\hline \multicolumn{3}{|c|}{$\begin{array}{c}\text { TABLE-3 } \\
\text { PHYSICAL PROPERTIES OF USED MATERIALS }\end{array}$} \\
\hline \multicolumn{2}{|c|}{ Used materials } & Physical properties \\
\hline \multicolumn{2}{|c|}{ Cement } & Density $3.15 \mathrm{~g} / \mathrm{cm}^{3}$ Fineness $3,378 \mathrm{~cm}^{2} / \mathrm{g}$ \\
\hline \multicolumn{2}{|c|}{ Natural sand } & $\begin{array}{l}\mathrm{G}_{\max } 5 \mathrm{~mm} \text {, Density } 2.60 \mathrm{~g} / \mathrm{cm}^{3} \text {, Absorbing } \\
\text { ratio } 1.80 \%\end{array}$ \\
\hline \multirow{2}{*}{$\begin{array}{l}\text { Recycled } \\
\text { sand }\end{array}$} & RS-I & $\begin{array}{l}\mathrm{G}_{\max } 5 \mathrm{~mm} \text {, Density } 2.60 \mathrm{~g} / \mathrm{cm}^{3} \text {, Absorbing } \\
\text { ratio } 6.22 \%\end{array}$ \\
\hline & RS-IV & $\begin{array}{l}\mathrm{G}_{\max } 4.5 \mathrm{~mm} \text {, Density } 2.48 \mathrm{~g} / \mathrm{cm}^{3} \text {, Absorbing } \\
\text { ratio } 2.57 \%\end{array}$ \\
\hline \multicolumn{2}{|c|}{ Coarse aggregate } & $\begin{array}{l}\mathrm{G}_{\max } 25 \mathrm{~mm} \text {, Density } 2.64 \mathrm{~g} / \mathrm{cm}^{3}, \text { Absorbing } \\
\text { ratio } 0.68 \%\end{array}$ \\
\hline
\end{tabular}

\section{RESULTS AND DISCUSSION}

Fluidity properties: It is shown the changes in unitwater content for satisfying the target slump (Fig. 3). In sand aggregate ratio (s/a) $45 \%$, when RS-I was used, the unitwater content for satisfying the fluidity increased largely as the replacement ratio of the recycled fine aggregate increased. On the other hand, when RS-IV was used, the unit-water content for satisfying the fluidity didn't change when the replacement ratio of recycled fine aggregate changed. Such tendency is due to the removal of impurity content, powder content and clod contained in the original material (RS-I) after going through the sand flux system.

Meanwhile, the changes in the unit-water content for satisfying the target slump of s/a $50 \%$ showed the similar tendency to that of s/a $45 \%$.

Strength properties: It is shown that the testing result of the compressive strength of the concrete using recycled sand depending on the concrete's age (Fig. 4). For s/a $45 \%$, the compressive strength of 28 day RS-I is in the range of 26.5$28.9(\mathrm{MPa})$ whereas the compressive strength of RS-IV is in the range of 29.6-31.6 (MPa). For RS-I, the development rate

\begin{tabular}{|c|c|c|c|c|c|c|c|c|c|c|c|}
\hline \multicolumn{12}{|c|}{$\begin{array}{l}\text { TABLE-2 } \\
\text { ND MIX PROPORTION OF CONCRETE }\end{array}$} \\
\hline \multirow{2}{*}{\multicolumn{2}{|c|}{ Type }} & \multirow{2}{*}{$\begin{array}{l}\mathrm{W} / \mathrm{C} \\
(\%)\end{array}$} & \multirow{2}{*}{$\begin{array}{l}\mathrm{s} / \mathrm{a} \\
(\%)\end{array}$} & \multicolumn{6}{|c|}{ Unit weight $\left(\mathrm{kg} / \mathrm{m}^{3}\right)$} & \multicolumn{2}{|c|}{ Measurement item } \\
\hline & & & & $\mathrm{W}$ & $\mathrm{C}$ & $S$ & RS-I & RS-IV & $\mathrm{G}$ & Fresh concrete & Hardende concrete \\
\hline & 0 & \multirow{12}{*}{55} & \multirow{8}{*}{45} & \multirow{8}{*}{185} & \multirow{8}{*}{336} & 829 & 0 & - & \multirow{8}{*}{1,032} & \multirow{12}{*}{$\begin{array}{l}\text { - Slump } \\
\text { - Air content } \\
\text { - Unit water content }\end{array}$} & \multirow{12}{*}{$\begin{array}{l}\text { - Compressive strength } \\
\text { - Elastic modulus } \\
\text { - Plastic shinrkage }\end{array}$} \\
\hline & 15 & & & & & 704 & 113 & - & & & \\
\hline RS-1 & 30 & & & & & 580 & 226 & - & & & \\
\hline & 50 & & & & & 414 & 376 & - & & & \\
\hline \multirow{4}{*}{ RS-IV } & 0 & & & & & 829 & - & 0 & & & \\
\hline & 15 & & & & & 704 & - & 119 & & & \\
\hline & 30 & & & & & 580 & - & 238 & & & \\
\hline & 50 & & & & & 414 & - & 397 & & & \\
\hline & 0 & & \multirow{4}{*}{50} & \multirow{4}{*}{185} & \multirow{4}{*}{336} & 921 & 0 & - & \multirow{4}{*}{938} & & \\
\hline & 15 & & & & & 645 & 251 & - & & & \\
\hline \multirow{2}{*}{ RS-IV } & 30 & & & & & 921 & - & 0 & & & \\
\hline & 50 & & & & & 645 & - & 265 & & & \\
\hline
\end{tabular}


of compressive strength significantly decreased as the replacement ratio increased. On the other hand, in RS-IV, the compressive strength developed up to $91 \%$ of the natural aggregate mixture even when the aggregate replacement ratio was $50 \%$. As it has been mentioned above, such tendency seemed to be due to the improved quality of recycled sand after going through the wet gravity separation system.
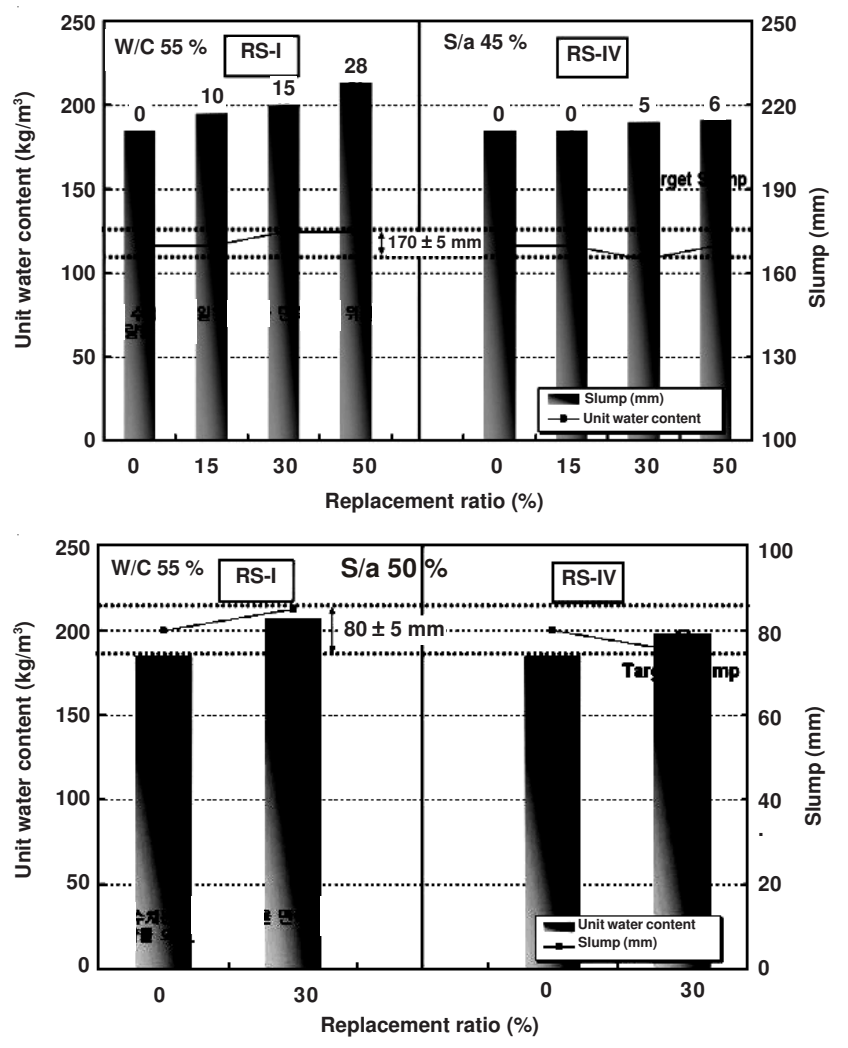

Fig. 3. Changes in fluidity properties of concrete
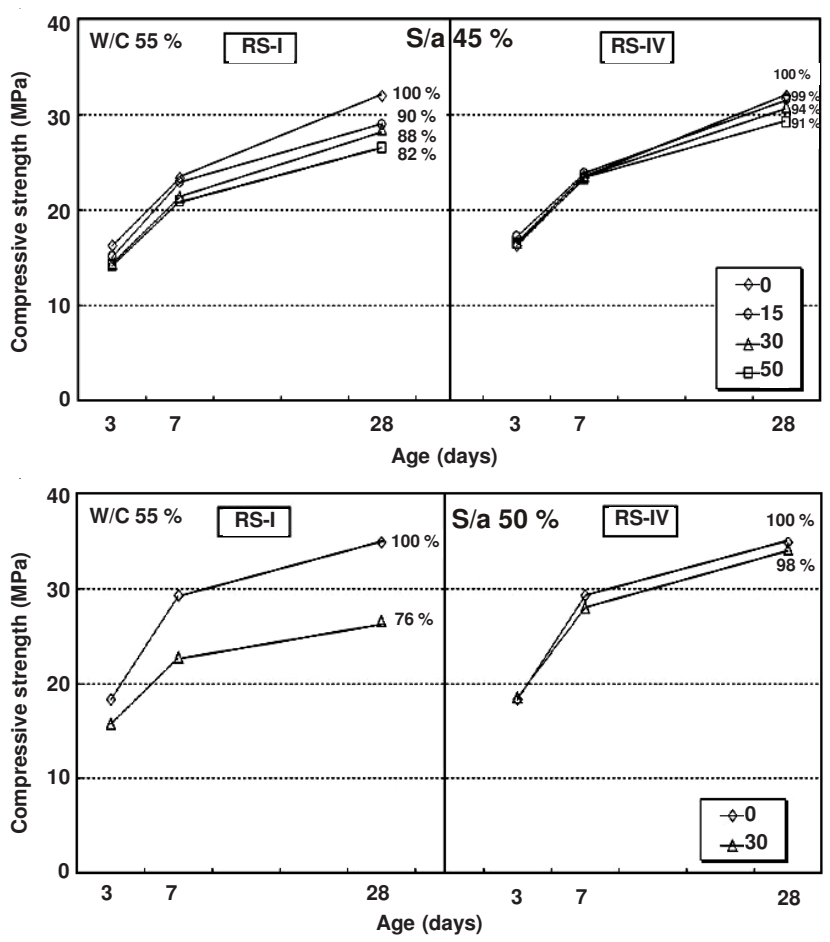

Fig. 4. Changes in compressive strength of concrete
Meanwhile, the testing of s/a $50 \%$ on the compressive strength of the concrete using recycled fine aggregate depending on the concrete's age showed similar tendency as that of s/a $45 \%$. For RS-I, the compressive strength decreased as the fine aggregate ratio increased. For RS-IV, on the other hand, no changes have been found when the fine aggregate ratio increased.

It is shown that the compressive strength ratio on the $28^{\text {th }}$ day depending on the fine aggregate ratio (Fig. 5).
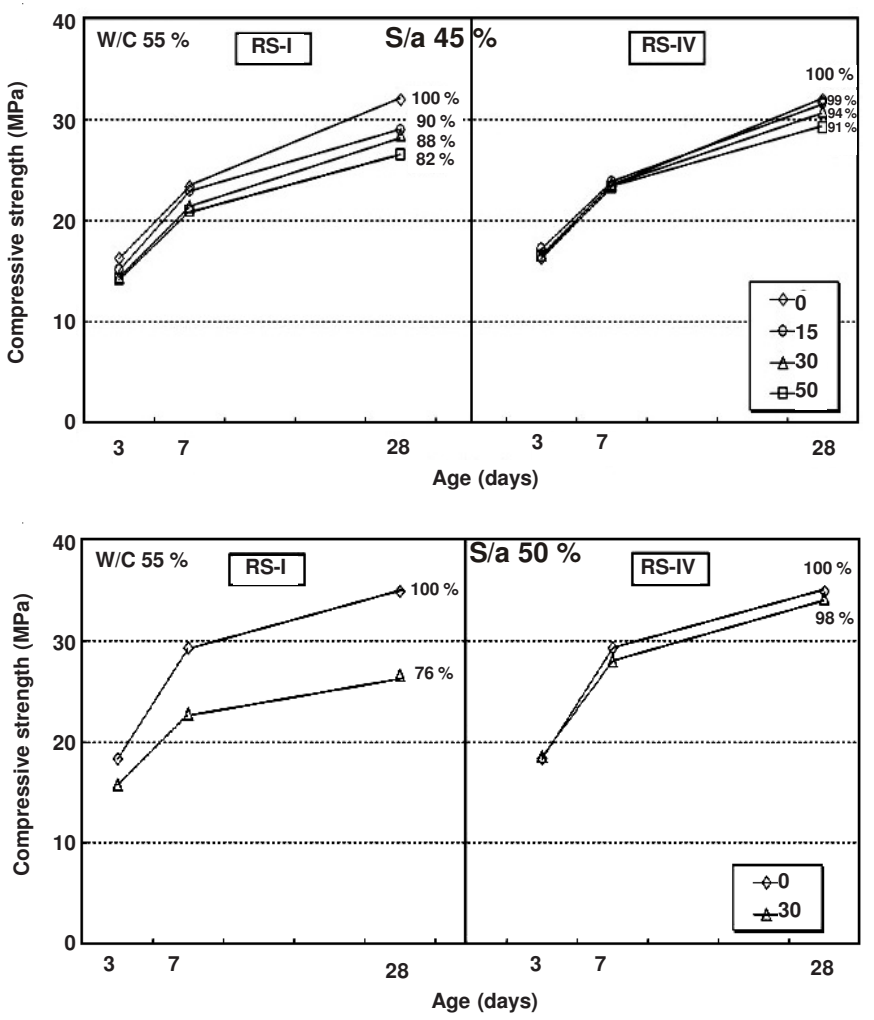

Fig. 5. Compressive strength ratio of concrete

Elastic modulus: The testing result of the elastic modulus of the concrete using recycled sand depending on the fine aggregate ratio (Fig. 6).

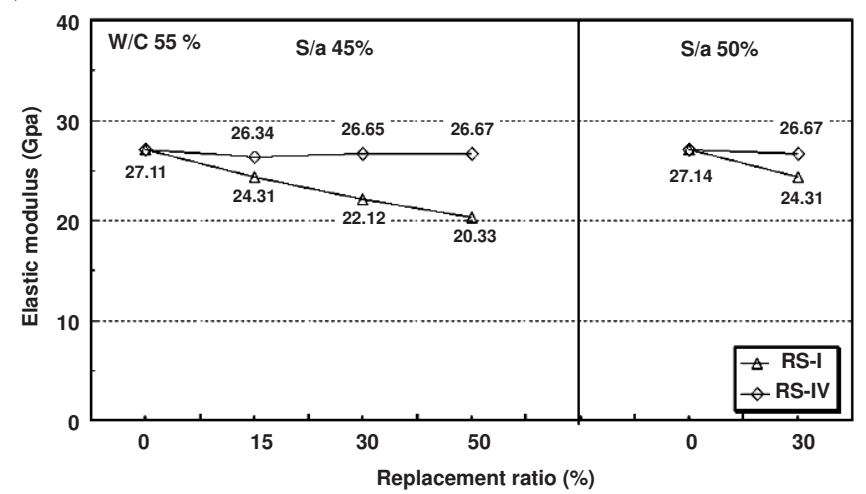

Fig. 6. Elastic modulus of concrete

The elastic modulus of RS-IV was similar to that of natural aggregate whereas the elastic modulus of RS-I decreased as the replacement ratio increased. Such tendency seemed to be due to the removal of the mortar attached to the surface of the aggregate with low elastic modulus. 
Shrinkage properties: It is shown the changes in the plastic shrinkage of the concrete depending on the replacement ratios and types of recycled fine aggregate (Fig. 7). As a result, it was found that the length and width of cracking was increased significantly at RS-I as the replacement ratio increased. On the other hand, the cracking did not occur up to $30 \%$ of aggregate replacement ratio at RS-IV. Such tendency seemed to be due to the removal of impurity content, powder content and clod contained in the original material(RS-I).

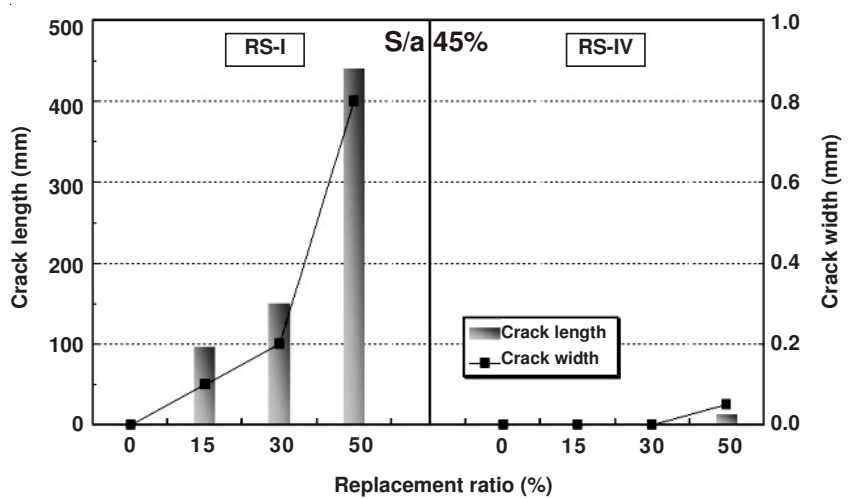

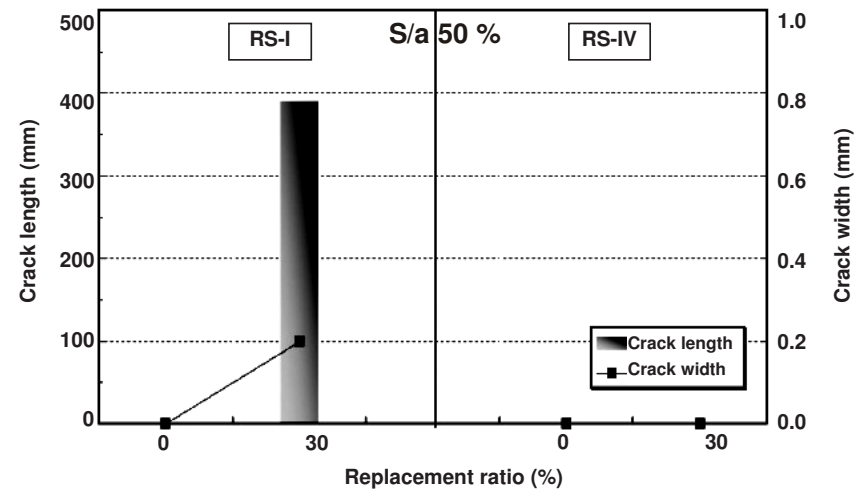

Fig. 7. Changes in plastic shrinkage

Meanwhile, the testing of s/a $50 \%$ on the changes of plastic shrinkage of concrete depending on the replacement ratios and types of recycled fined aggregate showed similar tendency as that of s/a $45 \%$. The length and width of cracking was decreased significantly at RS-I as the fine aggregate ratio increased. On the other hand, no changes have been found at RS-IV when the fine aggregate ratio increased.

\begin{tabular}{|c|c|c|c|c|c|c|c|c|}
\hline \multirow{2}{*}{$\begin{array}{l}\text { Recycled Sand } \\
\text { Replacement } \\
\text { Ratio }(\%) \\
\end{array}$} & \multicolumn{4}{|c|}{ S/a 45\% } & \multicolumn{4}{|c|}{ S/a 50\% } \\
\hline & \multicolumn{2}{|c|}{ RS-I (Before treatment) } & \multicolumn{2}{|c|}{ RS-IV (After treatment) } & \multicolumn{2}{|c|}{ RS-I (Before treatment) } & \multicolumn{2}{|l|}{ RS-IV (After treatment) } \\
\hline \multirow[t]{3}{*}{0} & & & & & & & & \\
\hline & Cracking length (mm) & 0 & Cracking length (mm) & 0 & Cracking length $(\mathrm{mm})$ & 0 & Cracking length $(\mathrm{mm})$ & 0 \\
\hline & Cracking width $(\mathrm{mm})$ & 0 & Cracking width $(\mathrm{mm})$ & 0 & Cracking width $(\mathrm{mm})$ & 0 & Cracking width (mm) & 0 \\
\hline \multirow[t]{3}{*}{15} & & & & & & & & \\
\hline & Cracking length $(\mathrm{mm})$ & 96 & Cracking length $(\mathrm{mm})$ & 0 & Cracking length $(\mathrm{mm})$ & & Cracking length $(\mathrm{mm})$ & \\
\hline & Cracking width $(\mathrm{mm})$ & 0.1 & Cracking width $(\mathrm{mm})$ & 0 & Cracking width $(\mathrm{mm})$ & & Cracking width $(\mathrm{mm})$ & \\
\hline \multirow[t]{3}{*}{30} & & & & & & & & \\
\hline & Cracking length $(\mathrm{mm})$ & 150 & Cracking length $(\mathrm{mm})$ & 0 & Cracking length $(\mathrm{mm})$ & 390 & Cracking length $(\mathrm{mm})$ & 0 \\
\hline & Cracking width (mm) & 0.2 & Cracking width $(\mathrm{mm})$ & 0 & Cracking width $(\mathrm{mm})$ & 0.2 & Cracking width $(\mathrm{mm})$ & 0 \\
\hline \multirow[t]{3}{*}{50} & & & & & & & & \\
\hline & Cracking length (mm) & 440 & Cracking length (mm) & 130 & Cracking length (mm) & & Cracking length $(\mathrm{mm})$ & \\
\hline & Cracking width $(\mathrm{mm})$ & 0.8 & Cracking width $(\mathrm{mm})$ & 0.05 & Cracking width $(\mathrm{mm})$ & & Cracking width (mm) & \\
\hline
\end{tabular}

Fig. 8. Plastic shrinkage testing results 
The appearance of the specimen for testing the plastic shrinkage of concrete depending on the types of recycled fine aggregate (Fig. 8).

Changes of compressive strength according to porosity: The compressive strength after finding out internal porosity through mercury intrusion porosimetry test results from comparison and review of concrete using only the natural sand and concrete produced from $50 \%$ replacement of RS-I and RS-IV aggregates (Fig. 9).

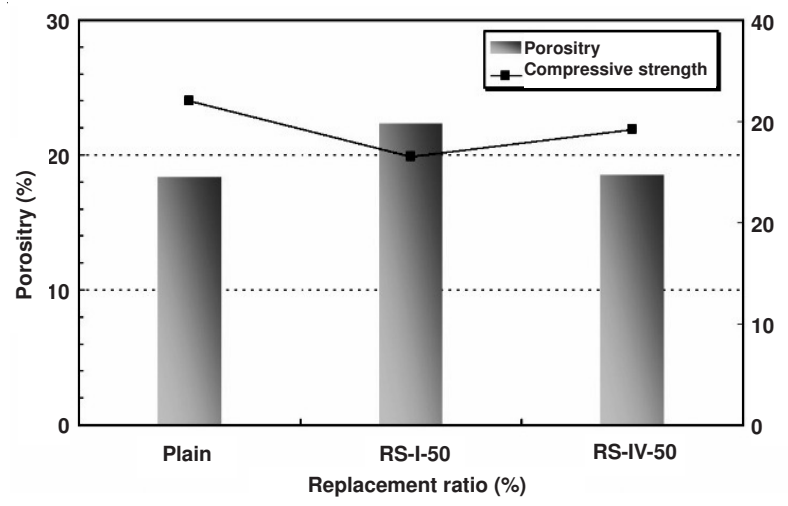

Fig. 9. Changes in porosity and compressive strength

As for the plain and RS-IV-50, 50 means fine aggregate $(50 \%)$ plus recycled aggregate $(50 \%)$, porosity was about $18 \%$. RS-I-50 produced porosity of about $22 \%$. As for RS-I50 of a high absorption rate, the pore structure was coarsened as the moisture absorbed in recycled sand permeated outside in the curing process of concrete, which resulted in high porosity. On the other hand, as for compressive strength, plain and RS-IV-50 produced 23.3-23.4 (MPa), which is a minor difference while RS-I-50 produced 20.9 MPa showing a downward tendency of compressive strength. It is seemed to come from removal of earth, clay, organic foreign materials and mortar on the surface of aggregate which took place while passing through the wet gravity separation and are barriers to compressive strength as well as the difference in porosity (Fig. 10).

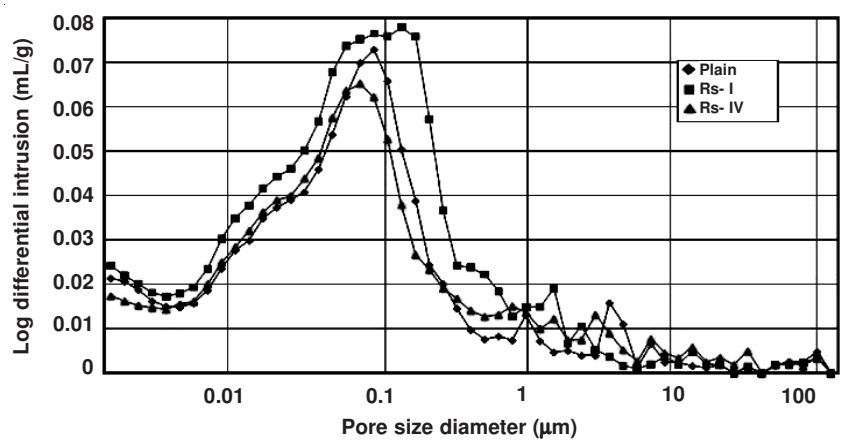

Fig. 10. Pore (defect) distribution

Depth of acceleration carbonation: It is shown the changes of depth of acceleration carbonation of concrete according to the types of recycled sand. As for s/a $45 \%$, the depth of plain was $0.45-1.50(\mathrm{~mm})$ and the depth according to replacement of RS-I was 0.75-7.00 ( $\mathrm{mm})$, which reveals the tendency that increasing replacement rate of RS-I relates to a high increase of carbonation depth (Fig. 11).
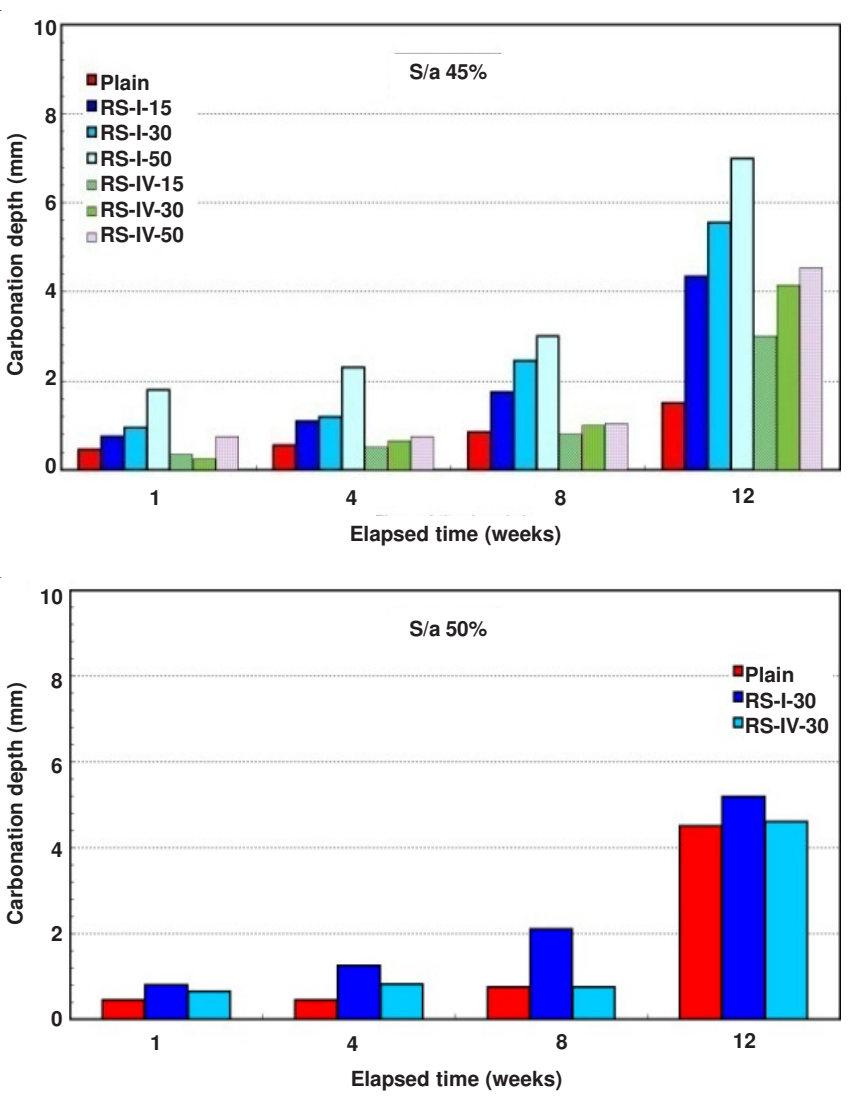

Fig. 11. Changes in depth of accelerated carbonation

Also as for RS-IV, the depth was 0.35-4.55 (mm), which shows that the carbonation depth was promoted more than that of plain, but it decreased when compared to RS-I. It is seemed to come from removal of mortar, earth and foreign materials on the surface of recycled sand, which are promoters of carbonation while passing through the wet gravity separation as well as the difference in porosity structure.

On the other hand, as for s/a $50 \%$, the range of depth of carbonation of plain was $0.45-4.50(\mathrm{~mm})$. The depth in RS-I was 0.80-5.20 (mm) and that of RS-IV was 0.65-4.60 (mm), which is an identical tendency found with s/a $45 \%$.

Penetration depth of chloride ions: It is shown that the change of penetration depth of chloride ions of concrete according to the types of recycled sand (Fig. 12).

The range of penetration depth of chloride ions of plain was $0-12.30(\mathrm{~mm})$ and that from replacement of RS-I was 1.20-15.30 (mm), which shows the tendency that increased replacement rate of RS-IV relates to high increase of penetration depth of chloride ions. Also, that of RS-IV was 0-14.30 $(\mathrm{mm})$, rather heightened penetration depth compared to plain but decreased penetration depth compared to RS-I.

On the other hand, as for s/a $50 \%$, the range of depth of chloride ions of Plain was 0.45-4.50 (mm). The depth in RSI was 0.80-5.20 (mm) and that of RS-IV was 0.65-4.60 (mm), which is an identical tendency found with s/a $45 \%$.

Resistance to chemical erosion: It is shown that the change of resistance to chemical erosion of concrete according to the types of recycled sand (Fig. 13). As a result from studying changes of resistance to chemical erosion according to the types and replacement rate of the recycled sand, concrete using 

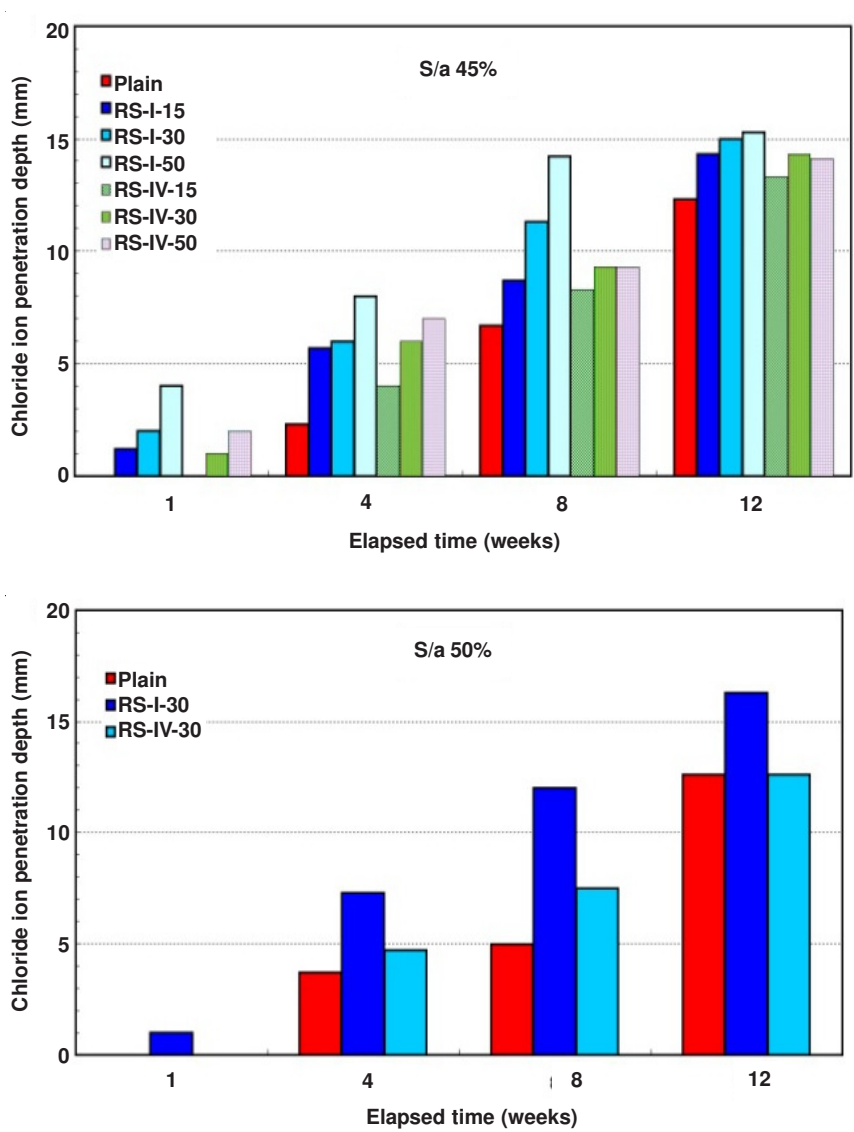

Fig. 12. Chloride ion penetration depth
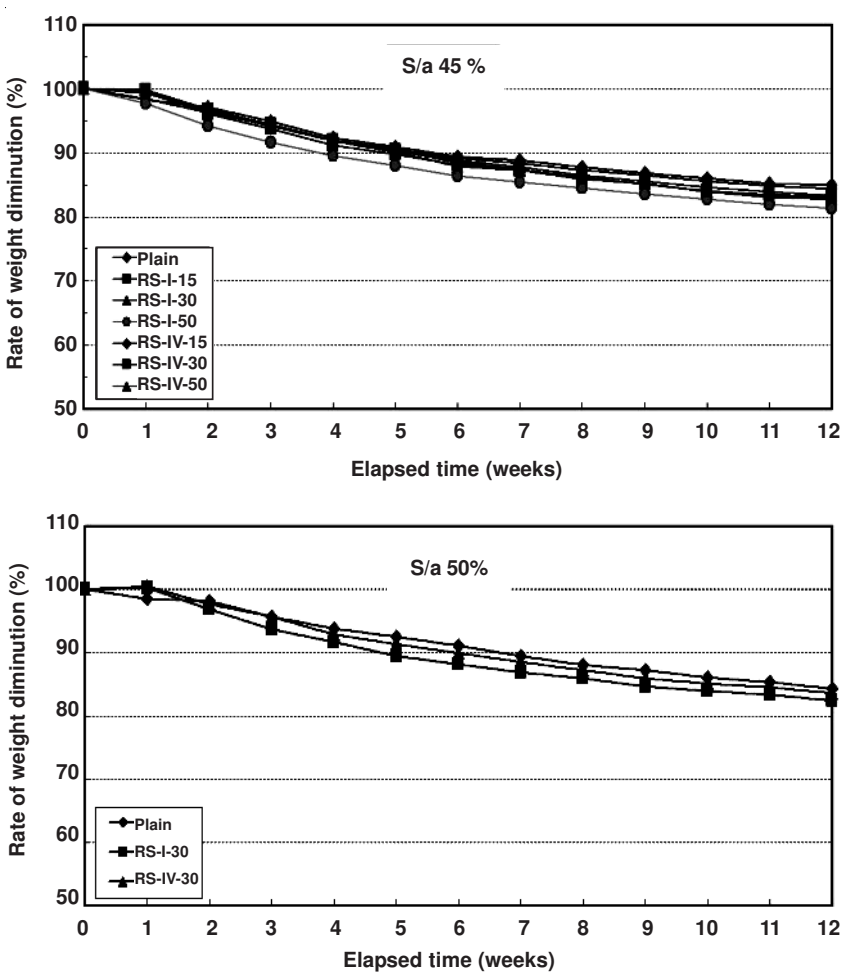

Fig. 13. Sulfate resistance

only the natural sand produced excellent resistance to chemical erosion. But the difference was small, which leads to a conclusion that the impact of the types and replacement rate of aggregates is insignificant.

\section{Conclusion}

To contribute to increase the use of and to add value to recycled sand, an experimental research has been conducted based on various fundamental properties of recycled sand, which were the fluidity, strength and durability properties of recycled aggregate concrete depending on the replacement and aggregate ratios of the recycled sand. The conclusion was followed:

1) The result of testing the concrete with the recycled fine aggregate was as followed: When RS-I was used, the unitwater content for satisfying the fluidity increased significantly as the replacement ratio of the recycled fine aggregate increased. On the other hand, when RS-IV was used, almost no change has been seen in the unit-water content for satisfying the fluidity when the replacement ratio of the recycled fine aggregate changed.

With RS-I, the development rate of compressive strength decreased significantly decreased as the replacement ratio increased. With RS-IV, on the other hand, the compressive strength developed up to $91 \%$ of the natural fine aggregate mixture even when the replacement ratio of aggregate is $50 \%$.

As a result of plastic shrinkage test, it was found that with RS-I, the length and width of cracking increased significantly as the replacement ratio increased, while no cracking has occurred up to $30 \%$ of aggregate replacement ratio at RS-IV.

As a result of testing the inner porosity through mercury intrusion Penetration, it was found the porosity of plain and RS-IV was about $18 \%$ whereas the porosity of RS-I was about $22 \%$.

Based on the research of changes of the depth of acceleration carbonation and penetration of chloride ions, those of concrete using RS-IV were decreased compared to concrete using RS-I. Also as for the resistance to chemical erosion, there was no significant impact at the types and replacement rate of aggregates.

2) It could be seen that the recycled sand produced through the wet gravity separation system may also be produced at construction sites without much problem meeting the targeted quality level. The wet gravity separation system suggested in the study can be installed and operated without making any change to the existing manufacturing system. This research suggested that the the proposed system could be practically used in domestic market in construction wastes treatment and demonstrated the superiority of the system.

\section{ACKNOWLEDGEMENTS}

This research was accomplished by support of $05 \mathrm{R} \& \mathrm{D}$ project for critical technology of construction (Project No.: 05 construction core D07) in Ministry of land, transport and maritime affairs.

\section{REFERENCES}

1. Jaehwan Kim, A Study on the Manufacture and High Value-Added Use of High-Quality Recycled Fine Aggregate for Environmental Load Reduction Concrete, Chungnam National University, Doctoral Dissertation, Daejeon, Republic of Korea (2006).

2. H.Y. Song, S.S. Lee, D.H. Lee, J.W. Kim, H. Lim and J.S. Lee, The Korea Institute of Building Construction, 7, 23 (2007). 
3. H.Y. Song, S.S. Lee, K.W. Kang, J.W. Kim, H. Lim and J.S. Lee, An Experimental Study on the Quality Evaluation of the Recycled Sand and Mortar Produced from Sand Flux Apparatus, Korea Concrete Institute, Spring Conference, vol. 5, p. 641 (2007).

4. H.Y. Song, H. Lim and S.S. Lee, A Study on the Quality Properties of Recycled Fine Aggregate Using Manufacturing System by Wet Gravity Separation, Architectural Insitute of Korea, Vol. 24, p. 117 (2008).

5. H.Y. Song, S.S. Lee, D.H. Lee, G.S. Bae and J.H. Lee, An Experimental Study on the Quality Estimation of the Mortar and Concrete using High-Quality Recycled Sand Producted from the Manufacturing System by Wet Gravity Separation, Architectural Insitute of Korea, pp 531534 (2008).
6. H.Y. Song, S.S. Lee, J.S. Lee, H.N. Rho and J.H. Lee, An Experimental Study on the Quality Estimation of the Mortar using High-Quality Recycled Sand Producted from the Manufacturing System by Wet Gravity, The Korea institute of Building Construction, Vol. 8, p. 103 (2008).

7. H.Y. Song, S.S. Lee, G.S. Bae, J.H. Lee and Y.S. Lee, An Experimental Study on the Quality Estimation of the High-Quality of Recycled Sand by the Differences Between Small-Large Sand Flux Apparatus, The Korea Institute of Building Construction, Vol. 9, p. 81 (2009). 